\title{
CLIMATE SIGNALS OF THE NORTH ATLANTIC OSCILLATION DETECTED IN THE CARPATHIAN BASIN
}

\author{
J. BARTHOLY* - R. PONGRÁCZ - GY. GELYBÓ \\ Department of Meteorology, Eötvös Loránd University \\ Pázmány P. st. 1/a. Budapest, H-1117, Hungary \\ (phone: +36-1-372-2945; fax: +36-1-372-2904) \\ *Corresponding author \\ e-mail: bari@ludens.elte.hu \\ (Received $9^{\text {th }}$ September 2009 ; accepted $9^{\text {th }}$ November 2009)
}

\begin{abstract}
North Atlantic Oscillation (NAO) can be considered as the primary large scale atmospheric driver of the European climate, especially in winter. In the present paper, first, NAO effects on regional circulation represented by the circulation patterns (CP) using the Hess-Brezowsky Grosswetterlagen (HBGWL) and Péczely classification systems are analyzed. Our results for the 1901-2000 period suggest that the zonal/meridional $\mathrm{CP}$ classes occur more often during NAO+/NAO- phase in all seasons in case of both classification systems. Furthermore, Cyclonic/Anticyclonic CP types are more/less frequent in $\mathrm{NAO}-$ phase, and less/more frequent in NAO+ phase than in case of normal conditions. Then, NAO and $\mathrm{CP}$ joint effects on local temperature and precipitation time series are evaluated for the 20th century. In general, NAO- phase is associated with cold and wet winters, whereas NAO+ phase implies warm and dry winters in the Carpathian basin. If considering cyclone or anticyclone dominance over the region, $\mathrm{NAO}+$ is associated with dry and warm winters, and dry summers in case of Anticyclonic CP class, whereas NAO- phase implies wet and cold winters and autumns in the Carpathian basin (either for the Péczely or the HBGWL classification systems). When Cyclonic CP class occurs using the HBGWL classification system (i) winters tend to be drier and warmer than usual, springs tend to be drier and colder than usual in NAO+ phase; (ii) springs and autumns tend to be wetter than usual, winters tend to be colder than usual in NAO- phase. If the Péczely classification system is used then Cyclonic CP class is associated with (i) significantly warmer winters and colder springs during NAO+ phase; (ii) significantly wetter and colder winters, and wetter autumns during NAO- phase.
\end{abstract}

Keywords: North Atlantic Oscillation, Hess-Brezowsky Grosswetterlagen, Péczely CP types, temperature, precipitation

\section{Introduction}

Several oscillation phenomena have been recognized $[1,24]$ in the climate system both in the low- and midlatitudes. In the tropics, El Nino/Southern Oscillation (ENSO) is the leading climatic mode with warm and cold phases [17] both having world-wide ecological, economical and social consequences, especially in strong cases [3]. Let us mention here only some examples of these environmental impacts: fish catches off the coast of Peru, maize harvests in Zimbabwe and the occurrence of malaria in Columbia can all be shown to depend on the ENSO [2]. One of the extratropical large scale oscillations is the North Atlantic Oscillation (NAO) that performs great importance in determining climatic variables of Europe $[6,12]$, especially in winter. Certainly, climatic conditions affect the European environment and biosphere. The positive NAO phase occurs when the Icelandic low-pressure center is lower than usual while the subtropical high-pressure center near the Azores tends to be higher than usual thus resulting in a strong meridional pressure gradient over the North Atlantic region. This strong gradient is associated with intense westerly flow over the North Atlantic region, and also, a northward shift in the general tracks of midlatitude cyclones [8, 14, 21, 25]. 
Thus, precipitation tends to increase in Northern Europe, and dry conditions occur in the Mediterranean region [13, 20, 22]. During this positive phase, warmer-than-usual conditions are observed in Northern and Central Europe, which can be explained by the low-level advection over the Atlantic [7]. During the negative NAO phase the meridional pressure gradient is weaker, thus the weakened westerlies across the North Atlantic region result in cold and dry conditions in Northern Europe and wet conditions in the Mediterranean region [8].

In the present study, we are focusing on the teleconnections of NAO, namely, climatic impacts of this large scale phenomenon to the Carpathian basin both on regional and local scales are analyzed. Regional circulation is represented by circulation patterns (CPs): the Hess-Brezowsky Grosswetterlagen (HBGWL) [4, 5] and the Péczely $\mathrm{CP}$ types $[15,16]$. On local scale temperature and precipitation time series observed in the 20th century are used. After presenting the database in Section 2, the statistical relationship between NAO and CP types is discussed in Section 3. Then, the joint effect of NAO and CP types on the local climate variables of the Carpathian basin is analyzed in Section 4. Finally, the main conclusions are summarized in Section 5.

\section{Data}

\section{Monthly NAO index time series}

North Atlantic Oscillation can be characterized by the monthly NAO index, which is the difference between the normalized sea level pressure over Gibraltar and that of Southwestern Iceland [9, 23]. The 1901-2000 time series used in the present study is available via Internet (from the data archive of the Climatic Research Unit, University of East Anglia). The large positive and negative index values are separated using the standard deviation of the entire time series $(\sigma=1.71)$. Hence NAO+ and NAO- phases are defined when the NAO index is larger than 1.71 (208 months) and smaller than 1.71 (182 months), respectively. In the present analysis normal conditions are defined when the NAO index value is between -1.71 and 1.71 .

\section{Daily catalogue of CP types}

Two different CP classification systems are used, namely, the Hess-Brezowsky Grosswetterlagen $[4,5]$, and the Péczely CP types [15, 16]. Both of them are defined to characterize the large scale structure of the air pressure systems over the North Atlantic region and the European continent using daily sea level pressure data. The HessBrezowsky CP types (HBGWL) consider the Central European aspects of the European circulation while the Péczely types focuses more on the Carpathian basin particularly.

According to the HBGWL classification system CP types are classified into 29 types based on the dominant direction of air mass movements and the presence of cyclones or anticyclones in different European subregions (Table 1). The available dataset consists of daily CP codes from 1901 to 2000 and is published monthly in the journal "Die Grosswetterlagen Europas" of the German Meteorological Service. In the present analysis, we use $\mathrm{CP}$ classes aggregated using various aspects. (1) According to the main air flow directions (W, SW, NW, N, NE, E, SE, S), eight different groups can be distinguished and two extra classes where the circulation is controlled by Central European pattern. (2) Circulation characteristics can be another factor, thus zonal, halfmeridional and meridional $\mathrm{CP}$ classes were defined. Zonal $\mathrm{CP}$ class includes $4 \mathrm{HB}$ types 
(Wa,Wz, Ws, Ww), meridional $\mathrm{CP}$ class consists of 18 different $\mathrm{HB}$ types $(\mathrm{Na}, \mathrm{Nz}$, $\mathrm{HNa}, \mathrm{HNz}, \mathrm{HB}, \mathrm{TRM}, \mathrm{NEa}, \mathrm{NEz}, \mathrm{HFa}, \mathrm{HFz}, \mathrm{HNFa}, \mathrm{HNFz}, \mathrm{SEa}, \mathrm{SEz}, \mathrm{Sa}, \mathrm{Sz}, \mathrm{TB}$, TRW), and the other 7 HB types (SWa, SWz, NWa, NWz, HM, BM, TM) compose the half-meridional CP class. (3) Cyclonic and anticyclonic CP types are separated into classes consisting 14 (Wz, SWz, NWz, TM, Nz, HNz, TrM, NEz, HFz, HNFz, SEz, Sz, $\mathrm{TB}, \mathrm{TrW}$ ) and 12 (Wa, SWa, NWa, HM, Na, HNa, HB, NEa, HFa, HNFa, SEa, Sa) types, respectively.

Table 1. Macrocirculation types defined in the HBGWL system.

\begin{tabular}{|c|c|c|}
\hline Circulation type & Main flow direction & Macrosynoptic type (notation) \\
\hline Zonal & West $(\mathrm{W})$ & West anticyclonic (Wa) \\
\hline & & West cyclonic (Wz) \\
\hline & & Southern West (Ws) \\
\hline & & Angleformed West (Ww) \\
\hline \multirow[t]{7}{*}{ Half-Meridional } & Southwest (SW) & Southwest anticyclonic (SWa) \\
\hline & & Southwest cyclonic (SWz) \\
\hline & Northwest (NW) & Northwest anticyclonic (NWa) \\
\hline & & Northwest cyclonic (NWz) \\
\hline & Central European high (HM) & Central European high (HM) \\
\hline & & Central European ridge (BM) \\
\hline & Central European low (TM) & Central European low (TM) \\
\hline \multirow[t]{18}{*}{ Meridional } & North (N) & North anticyclonic $(\mathrm{Na})$ \\
\hline & & North cyclonic $(\mathrm{Nz})$ \\
\hline & & North, Iceland high, anticyclonic ( $\mathrm{HNa})$ \\
\hline & & North, Iceland high, cyclonic (HNz) \\
\hline & & British Islands high (HB) \\
\hline & & Central European Trough (TRM) \\
\hline & Northeast (NE) & Northeast anticyclonic (NEa) \\
\hline & & Northeast cyclonic (NEz) \\
\hline & East (E) & Fennoscandian high anticyclonic (HFa) \\
\hline & & Fennoscandian high cyclonic (HFz) \\
\hline & & Norwegian Sea/Fennoscandian high anticyclonic (HNFa) \\
\hline & & Norwegian Sea/Fennoscandian high cyclonic (HNFz) \\
\hline & Southeast (SE) & Southeast anticyclonic (SEa) \\
\hline & & Southeast cyclonic (SEz) \\
\hline & South (S) & South anticyclonic $(\mathrm{Sa})$ \\
\hline & & South cyclonic $(\mathrm{Sz})$ \\
\hline & & British Islands low (TB) \\
\hline & & Western European Trough (TRW) \\
\hline
\end{tabular}

The Péczely classification system was defined by György Péczely, a Hungarian climatologist (1924-1984), on the base of the geographical location of cyclones or anticyclones relative to the Carpathian basin [15, 16]. Altogether 13 types were composed as listed in Table 2. In the present analysis individual $\mathrm{CP}$ types are grouped according to (1) the main directions: Meridional, northern types (mCc, $\mathrm{AB}, \mathrm{CMc}$ ), Meridional, southern types ( $\mathrm{mCw}$, Ae, $\mathrm{CMw})$, Zonal, western types ( $\mathrm{zC}, \mathrm{Aw}, \mathrm{As})$, Zonal, eastern types (An, AF), Central types (A, C), and (2) the cyclonic or anticyclonic dominance consisting 6 (mCc, CMs, mCw, CMw, zC, C) and 7 ( $\mathrm{AB}, \mathrm{Ae}, \mathrm{Aw}, \mathrm{As}, \mathrm{An}$, $\mathrm{AF}, \mathrm{A})$ types, respectively. Daily time series of the Péczely $\mathrm{CP}$ types are available for the period 1901-2000 [10, 11, 16]. 
Table 2. Macrocirculation types defined in the Péczely CP system

\begin{tabular}{c|c|c}
\hline Main type & Macrosynoptic type & Notation \\
\hline Meridional, northern types & Cold front with meridional flow & $\mathrm{mCc}$ \\
& Anticyclone over the British Isles & $\mathrm{AB}$ \\
& Cold front arising from a Mediterranean cyclone & $\mathrm{CMc}$ \\
\hline Meridional, southern types & Warm front arising from a meridional cyclone & $\mathrm{mCw}$ \\
& Anticyclone located east of the Carpathian Basin & Ae \\
& Warm front arising from a Mediterranean cyclone & CMw \\
\hline Zonal, western types & Zonal cyclone & $\mathrm{zC}$ \\
& Anticyclone located west of the Carpathian Basin & Aw \\
& Anticyclone located south of the Carpathian Basin & As \\
\hline Zonal, eastern types & Anticyclone located north of the Carpathian Basin & An \\
& Anticyclone located over the Scandinavian Peninsula & AF \\
\hline Central types & Anticyclone located over the Carpathian Basin & A \\
& Cyclone located above the Carpathian Basin & C \\
\hline
\end{tabular}

\section{Local-scale daily observations}

Daily temperature and precipitation time series observed in Budapest $\left(47.5^{\circ} \mathrm{N}, 19^{\circ} \mathrm{E}\right)$ are used to represent the local climate conditions in the Carpathian basin. Daily minimum, mean, and maximum temperature values and daily precipitation amounts of Budapest for the entire 20th century (1901-2000) are available from the Hungarian Meteorological Service (www.met.hu).

\section{Analysis of CP types during different NAO phases}

First, the relationship between NAO and regional circulation patterns is analyzed. For this purpose, annual and monthly frequencies of each CP class is determined for both the HBGWL and the Péczely systems on the basis of CP types' occurrence during the 1901-2000 period. Then, differences of CP class relative frequencies in case of NAO- and NAO+ are calculated relative to the normal conditions (defined by the standard deviation as described in the previous section). Since the positive NAO phase implies strong pressure gradient over the North Atlantic thus resulting in enhanced westerly flow (Hurrell, 1995; Hurrell et al., 2003), therefore, special focus is given to the zonal and meridional patterns. Annual and seasonal frequency differences are summarized in Table 3 for zonal and meridional CP classes from the HBGWL and Péczely systems. In general, the differences are opposite to each other in case of NAO+ and NAO-, which highlight the remarkable difference of these two phases. The zonal $\mathrm{CP}$ class occurs more often during $\mathrm{NAO}+$ phase, and meridional $\mathrm{CP}$ class during NAOphase in all seasons. The frequency difference values are smaller in case of the Péczely classification system than in case of the HBGWL system. This can be explained by the geographical target area of the Péczely system, which focuses more on the Carpathian basin located in a larger distance from the NAO action centers than the target area of the HBGWL. The largest difference values (mostly exceeding 10\%) are observed during winter, which is the most relevant season in terms of NAO-associated climatic effects (Hurrell et al., 2003; Osborn, 2006). Furthermore, the occurrence difference between NAO- and NAO+ phases is also large in autumn, whereas it is the smallest in summer. 
Table 3. Difference in seasonal and annual occurrences of zonal and meridional CP classes during NAO negative and positive phases relative to the normal conditions (defined by the standard deviation), 1901-2000. In case of the HBGWL system, zonal CP class consists of the following CP types: $W a, W z, W s, W w$, and meridional CP class: $N a, N z, H N a, H N z, H B$, $T R M, N E a, N E z, H F a, H F z, H N F a, H N F z, S E a, S E z, S a, S z, T B$, TRW. In case of the Péczely $C P$ classification system, zonal and meridional $C P$ classes contain $z C, A w, A s$, and $m C c, A B$, $C M c, m C w, A e, C M w$, respectively.

\begin{tabular}{c|c|c|c|c|c|c|c}
\hline CP class & $\begin{array}{c}\text { Classification } \\
\text { system }\end{array}$ & $\begin{array}{c}\text { NAO } \\
\text { phase }\end{array}$ & $\begin{array}{c}\text { Winter } \\
\text { (DJF) }\end{array}$ & $\begin{array}{c}\text { Spring } \\
\text { (MAM) }\end{array}$ & $\begin{array}{c}\text { Summer } \\
\text { (JJA) }\end{array}$ & $\begin{array}{c}\text { Autumn } \\
\text { (SON) }\end{array}$ & Annual \\
\hline Zonal & HBGWL & NAO- & $-13 \%$ & $-10 \%$ & $-3 \%$ & $-14 \%$ & $-11 \%$ \\
& & NAO+ & $16 \%$ & $15 \%$ & $13 \%$ & $11 \%$ & $14 \%$ \\
& Péczely CP & NAO- & $-12 \%$ & $-6 \%$ & $-2 \%$ & $-7 \%$ & $-7 \%$ \\
& & NAO+ & $11 \%$ & $10 \%$ & $8 \%$ & $9 \%$ & $9 \%$ \\
Meridional & \multirow{2}{*}{ HBGWL } & NAO- & $26 \%$ & $17 \%$ & $11 \%$ & $22 \%$ & $19 \%$ \\
& & NAO+ & $-18 \%$ & $-21 \%$ & $-17 \%$ & $-15 \%$ & $-18 \%$ \\
& \multirow{2}{*}{ Péczely CP } & NAO- & $9 \%$ & $4 \%$ & $11 \%$ & $9 \%$ & $8 \%$ \\
& & NAO+ & $-10 \%$ & $-7 \%$ & $-8 \%$ & $-11 \%$ & $-7 \%$ \\
\hline
\end{tabular}

Fig. 1 shows the winter mean pressure fields for the zonal and meridional CP classes during NAO- and NAO+ phases, which are characterized by similar structures in case of HBGWL and Péczely classification systems. The composite maps of the NAO+ phase clearly illustrate the strong pressure gradient over the North Atlantic, in case of the zonal patterns the average pressure difference between the Icelandic Low and the Azores High is $38 \mathrm{hPa}$, and it is $34 \mathrm{hPa}$ in case of the meridional patterns. Much smaller pressure difference can be seen on the NAO- composite maps, not exceeding $20 \mathrm{hPa}$ (even in the zonal CP maps) over the North Atlantic region.

Another aspect is also evaluated, namely, the frequency differences of the cyclonic and anticyclonic CP classes. In the Péczely classification system cyclonic CP types are more frequent in NAO- phase, and more rare in NAO+ phase in each season than in case of normal conditions, the largest differences are found in summer (13\% and $-10 \%$, respectively) and the smallest in winter (7\% and $-7 \%$, respectively). Opposite to this, anticyclonic $\mathrm{CP}$ types tend to occur more rarely in NAO- phase and more often in NAO+ phase than in normal conditions. Since all CP types are either cyclonic or anticyclonic according to the Péczely classification system, the differences are the same but with opposite signs. In the HBGWL system the largest frequency difference of cyclonic CP types during NAO- phase is also in summer (9\%), while during NAO+ phase it can be observed in Spring $(-10 \%)$. Similarly to this, for the anticyclonic types the largest difference is in summer $(-9 \%)$ and in spring $(7 \%)$ in case of NAO- and $\mathrm{NAO}+$ phases, respectively. 


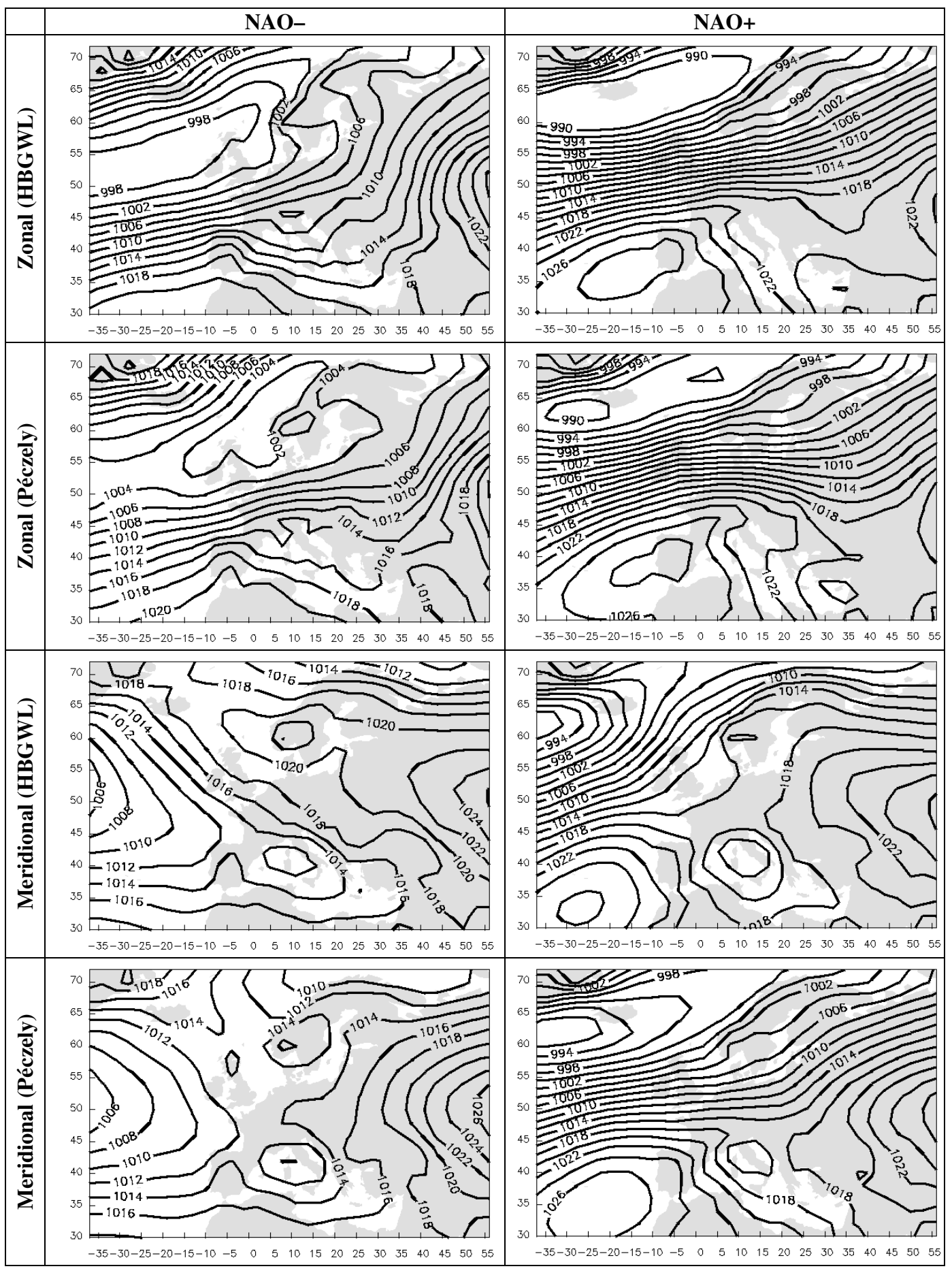

Figure 1. Winter mean sea level pressure field during NAO negative and positive phases relative to the normal conditions (defined by the standard deviation). In case of the HBGWL system, zonal CP class consists of the following CP types: $W a, W z, W s, W w$, and meridional CP class: $N a, N z, H N a, H N z, H B, T R M, N E a, N E z, H F a, H F z, H N F a, H N F z, S E a, S E z, S a, S z, T B$, $T R W$. In case of the Péczely $C P$ classification system, zonal and meridional CP classes contain $z C, A w, A s$, and $m C c, A B, C M c, m C w, A e, C M w$, respectively. 


\section{Analysis of local climate conditions}

The joint effects of NAO phases and CP types on local climatic conditions are analyzed using temperature and precipitation time series for the 20th century from Budapest. This meteorological station is used in the present paper since it well represents the Carpathian basin in general. The daily minimum, mean, and maximum temperature values as well, as daily precipitation amounts are averaged in case of each $\mathrm{CP}$ classes for the HBGWL and the Péczely classification systems. Daily average values are calculated separately for the NAO- and NAO+ phases, and the normal conditions (defined by the standard deviation of NAO index time series as described in 'Data' section).

\section{Temperature}

$\mathrm{CP}$-class-wise temperature differences for the NAO- and NAO+ phases relative to the normal conditions are shown in Table 4 (using the HBGWL system) and Table 5 (using the Péczely CP system) for daily mean temperature (in the upper large cell), and the minimum and maximum temperature values (in the lower small cells on the left and on the right, respectively). Bold values with grey background indicate significant differences at 0.05 level. In general, the climate of the Carpathian basin is warmer than usual during NAO+ phase, and colder than usual during NAO- phase [18]. According to the temperature difference values shown in Tables 4 and 5, most of the significant differences are found in winter, which can be explained by the fact that NAO is the primary large scale atmospheric driver of the European climate mostly in this season [8, 19]. The largest temperature decrease (exceeding $2.5^{\circ} \mathrm{C}$ on average!) in the Carpathian basin during NAO- phase is observed in winter when the northern $\mathrm{CP}$ classes occur both in case of the Péczely and HBGWL classification systems. The largest winter temperature increase associated with $\mathrm{NAO}+$ phase is observed in case of the Central $\mathrm{CP}$ class of the Péczely system $\left(1.8{ }^{\circ} \mathrm{C}, 1.6{ }^{\circ} \mathrm{C}\right.$, and $1.4{ }^{\circ} \mathrm{C}$ for the minimum, mean, and maximum temperature, respectively), and Eastern CP class of the HBGWL system (2.8 ${ }^{\circ} \mathrm{C}, 3.0{ }^{\circ} \mathrm{C}$, and $2.9{ }^{\circ} \mathrm{C}$ for the minimum, mean, and maximum temperature, respectively).

In spring, the largest significant temperature decrease in NAO- phase is detected when (i) Western CP class occur according to the Péczely system (cooling of all the temperature parameters exceeds $1.4{ }^{\circ} \mathrm{C}$ on century-wise average, although only daily minimum and mean temperatures are significant), or (ii) HM type (Central European high) occurs according to the HBGWL system (the temperature is lower by $2.3{ }^{\circ} \mathrm{C}, 2.9$ ${ }^{\circ} \mathrm{C}$, and $3.5 \mathrm{C}$ than usual on average in case of the daily minimum, mean, and maximum temperature, respectively). The significant temperature changes are also negative for the NAO+ phase in spring, the largest are detected for the Southern (both according to the Péczely and HBGWL system) and Southwestern (only for the HBGWL system) CP classes.

In summer, none of the average temperature differences relative to the normal conditions are significant at 0.05 level. Finally, in autumn significant differences are observed mostly in case of NAO- phase. The largest cooling exceeds $2.2^{\circ} \mathrm{C}$ on centurywise average for the daily minimum temperature, $2.5^{\circ} \mathrm{C}$ for the mean temperature, and $2.8{ }^{\circ} \mathrm{C}$ for the maximum temperature. It is detected when Central $\mathrm{CP}$ class occurs according to the Péczely system, or Northwestern CP class according to the HBGWL system. 
Table 4. HBGWL CP-class-wise average temperature differences $\left({ }^{\circ} \mathrm{C}\right)$ during the $N A O$ negative and positive phases relative to the normal conditions (defined by the standard deviation). Bold values with grey background indicate significant differences at 0.05 level.

\begin{tabular}{|c|c|c|c|c|c|c|c|c|c|c|c|c|c|c|c|c|}
\hline \multirow[t]{4}{*}{ CP classes } & \multicolumn{4}{|c|}{ Winter (DJF) } & \multicolumn{4}{|c|}{ Spring (MAM) } & \multicolumn{4}{|c|}{ Summer (JJA) } & \multicolumn{4}{|c|}{ Autumn (SON) } \\
\hline & \multirow{2}{*}{\multicolumn{2}{|c|}{$\begin{array}{c}\mathrm{NAO}- \\
\mathrm{T}_{\text {mean }} \\
\end{array}$}} & \multirow{2}{*}{\multicolumn{2}{|c|}{$\begin{array}{c}\mathrm{NAO+} \\
\mathrm{T}_{\text {mean }} \\
\end{array}$}} & \multirow{2}{*}{\multicolumn{2}{|c|}{$\frac{\mathrm{NAO}-}{\mathrm{T}_{\text {mean }}}$}} & \multirow{2}{*}{\multicolumn{2}{|c|}{$\begin{array}{c}\mathrm{NAO+} \\
\mathrm{T}_{\text {mean }} \\
\end{array}$}} & \multirow{2}{*}{\multicolumn{2}{|c|}{$\begin{array}{c}\mathrm{NAO}- \\
\mathrm{T}_{\text {mean }} \\
\end{array}$}} & \multirow{2}{*}{\multicolumn{2}{|c|}{$\frac{\mathrm{NAO}+}{\mathrm{T}_{\text {mean }}}$}} & \multirow{2}{*}{\multicolumn{2}{|c|}{$\begin{array}{c}\mathrm{NAO}- \\
\mathrm{T}_{\text {mean }} \\
\end{array}$}} & \multirow{2}{*}{\multicolumn{2}{|c|}{$\frac{\mathrm{NAO}+}{\mathrm{T}_{\text {mean }}}$}} \\
\hline & & & & & & & & & & & & & & & & \\
\hline & $\mathrm{T}_{\min }$ & $\mathrm{T}_{\max }$ & $\mathrm{T}_{\min }$ & $\mathrm{T}_{\max }$ & $\mathrm{T}_{\min }$ & $\mathrm{T}_{\max }$ & $\mathrm{T}_{\min }$ & $\mathrm{T}_{\max }$ & $\mathrm{T}_{\min }$ & $\mathrm{T}_{\max }$ & $\mathrm{T}_{\min }$ & $\mathrm{T}_{\max }$ & $\mathrm{T}_{\min }$ & $\mathrm{T}_{\max }$ & $\mathrm{T}_{\min }$ & $\mathrm{T}_{\max }$ \\
\hline \multirow[t]{2}{*}{ W } & \multicolumn{2}{|c|}{-0.2} & \multicolumn{2}{|c|}{0.5} & \multicolumn{2}{|c|}{-1.7} & \multicolumn{2}{|c|}{-1.1} & \multicolumn{2}{|c|}{-0.8} & \multicolumn{2}{|c|}{0.2} & \multicolumn{2}{|c|}{-0.5} & \multicolumn{2}{|c|}{-0.3} \\
\hline & -0.2 & -0.1 & 0.5 & 0.7 & -1.4 & -2.1 & -1.1 & -1.1 & -0.5 & -1.1 & 0.0 & 0.3 & -0.6 & -0.7 & -0.4 & 0.0 \\
\hline \multirow[t]{2}{*}{ SW } & \multicolumn{2}{|c|}{0.5} & & & & & & & & & & & & & -2 & 2 \\
\hline & 0.7 & 0.2 & 0.3 & 0.4 & 0.5 & 0.0 & -2.4 & -3.5 & 0.6 & -0.3 & 1.6 & 2.2 & -1.6 & -2.2 & -2.3 & -2.5 \\
\hline NW & & & & & & & & & & & & & & & -2 & .0 \\
\hline & -1.2 & -1.1 & 1.2 & 1.3 & -2.7 & -2.8 & 0.5 & 0.5 & -0.2 & -0.2 & 0.1 & -0.3 & -2.3 & -2.8 & -2.0 & -2.5 \\
\hline HM & & & & & & & & & & & & & & & -0 & 7 \\
\hline & -1.6 & -2.0 & 0.6 & 0.4 & -2.3 & -3.5 & -0.8 & -0.5 & -0.6 & -1.4 & 0.1 & 0.7 & -1.1 & -1.6 & -0.3 & -0.9 \\
\hline TM & & & & & & & & & & & & & & & 2 & \\
\hline & -1.9 & -1.5 & -0.2 & 0.8 & -1.3 & -2.2 & -1.1 & -2.0 & 0.0 & -0.4 & -- & -- & 1.8 & 3.3 & 3.4 & 0.6 \\
\hline $\mathrm{N}$ & & & & & & & & & & & & & & & -0 & 4 \\
\hline & -2.8 & -2.5 & 1.3 & 1.3 & -0.4 & -0.4 & -0.2 & 0.2 & -0.1 & -0.2 & 0.1 & 0.2 & -0.9 & -0.8 & -0.3 & -0.5 \\
\hline $\mathrm{NE}$ & & & & & & & & & & & & & & & -1 & .0 \\
\hline & 0.6 & 0.7 & -0.4 & 0.6 & -0.6 & -0.7 & 0.5 & 1.2 & 0.9 & 0.1 & -1.3 & -1.2 & 1.3 & 1.9 & -0.9 & -1.0 \\
\hline $\mathrm{E}$ & & & & & & & & & & & & & & & 0 & 2 \\
\hline & -0.8 & -0.5 & 2.8 & 2.9 & 1.0 & 1.2 & 0.4 & 0.8 & -1.5 & -2.4 & 0.3 & 0.4 & -1.1 & -1.9 & -0.2 & 1.2 \\
\hline SE & & & & & & & & & & & & & & & 2 & 1 \\
\hline & -0.6 & -0.5 & 1.4 & 1.2 & 2.1 & 1.9 & -0.9 & -1.7 & 1.1 & 1.8 & -- & -- & 1.2 & 1.8 & 1.7 & 2.0 \\
\hline S & & & & & & & & & & & & & & & 0 & \\
\hline & -0.4 & -0.5 & -0.5 & -0.7 & -0.3 & -0.4 & -2.5 & -2.6 & -0.2 & -0.8 & 1.2 & 1.7 & 1.0 & 0.9 & 0.7 & 0.8 \\
\hline Zonal & & & & & & & & & & & & & & & -0 & 3 \\
\hline & -0.2 & -0.1 & 0.5 & 0.7 & -1.4 & -2.1 & -1.1 & -1.1 & -0.5 & -1.1 & 0.0 & 0.3 & -0.6 & -0.7 & -0.4 & 0.0 \\
\hline Half- & & & & & & & & & & & & & & & & .1 \\
\hline Meridional & -1.2 & -1.4 & 0.5 & 0.5 & -1.5 & -2.5 & -0.8 & -0.9 & 0.0 & -0.5 & 0.3 & 0.6 & -1.3 & -1.8 & -0.9 & -1.3 \\
\hline Meridional & & & & & & & & & & & & & & & 0 & 9 \\
\hline & -1.9 & -1.7 & 1.2 & 1.2 & 0.0 & -0.2 & -0.6 & -0.5 & -0.4 & -0.8 & 0.1 & 0.2 & -0.2 & -0.4 & 0.6 & 1.1 \\
\hline Anticyclonic & & & & & & & & & & & & & & & & .1 \\
\hline & -1.8 & -1.9 & 1.6 & 1.4 & -0.7 & -1.1 & -0.5 & 0.2 & -0.7 & -1.1 & 0.0 & 0.7 & -1.1 & -1.7 & -1.0 & -1.3 \\
\hline Cyclonic & & & & & & & & & & & & & & & 0 & 9 \\
\hline & -2.0 & -1.9 & 1.1 & 1.6 & -0.2 & -0.7 & -1.1 & -1.3 & -0.2 & -0.7 & 0.1 & 0.2 & -0.8 & -1.1 & 0.6 & 1.3 \\
\hline
\end{tabular}

If considering cyclone or anticyclone dominance over the region, $\mathrm{NAO}+$ is associated with warm winters and cold springs in case of Cyclonic CP class, whereas NAO- implies cold winters in the Carpathian basin (either for the Péczely or the HBGWL classification systems). When Anticyclonic CP class occurs, winters are significantly warmer than usual (by $1.4-1.6{ }^{\circ} \mathrm{C}$ on century-wise average) in $\mathrm{NAO}+$ phase, and both winters and autumns are significantly colder than usual (by $1.8-2.3{ }^{\circ} \mathrm{C}$ and $1.0-1.7^{\circ} \mathrm{C}$, respectively) in $\mathrm{NAO}-$ phase. 
Table 5. Péczely CP-class-wise average temperature differences $\left({ }^{\circ} \mathrm{C}\right)$ during the $N A O$ negative and positive phases relative to the normal conditions (defined by the standard deviation). Bold values with grey background indicate significant differences at 0.05 level.

\begin{tabular}{|c|c|c|c|c|c|c|c|c|c|c|c|c|c|c|c|}
\hline \multirow[t]{4}{*}{ CP classes } & \multicolumn{3}{|c|}{ Winter (DJF) } & \multicolumn{4}{|c|}{ Spring (MAM) } & \multicolumn{4}{|c|}{ Summer (JJA) } & \multicolumn{4}{|c|}{ Autumn (SON) } \\
\hline & \multirow{2}{*}{$\begin{array}{c}\mathrm{NAO}- \\
\mathrm{T}_{\text {mean }} \\
\end{array}$} & \multicolumn{2}{|c|}{$\mathrm{NAO}+$} & \multicolumn{2}{|c|}{ NAO- } & \multicolumn{2}{|c|}{$\mathrm{NAO}+$} & \multicolumn{2}{|c|}{ NAO- } & \multicolumn{2}{|c|}{$\mathrm{NAO}+$} & \multicolumn{2}{|c|}{ NAO- } & \multicolumn{2}{|c|}{$\mathrm{NAO}+$} \\
\hline & & \multicolumn{2}{|c|}{$\mathrm{T}_{\text {mean }}$} & \multicolumn{2}{|c|}{$\mathrm{T}_{\text {mean }}$} & \multicolumn{2}{|c|}{$\mathrm{T}_{\text {mean }}$} & \multicolumn{2}{|c|}{$\mathrm{T}_{\text {mean }}$} & \multicolumn{2}{|c|}{$\mathrm{T}_{\text {mean }}$} & \multicolumn{2}{|c|}{$\mathrm{T}_{\text {mean }}$} & \multicolumn{2}{|c|}{$\mathrm{T}_{\text {mean }}$} \\
\hline & \begin{tabular}{l|l}
$\mathrm{T}_{\min }$ & $\mathrm{T}_{\max }$ \\
\end{tabular} & $\mathrm{T}_{\min }$ & $\mathrm{T}_{\max }$ & $\mathrm{T}_{\min }$ & $T_{\max }$ & $\mathrm{T}_{\min }$ & $\mathrm{T}_{\max }$ & $\mathrm{T}_{\min }$ & $\mathrm{T}_{\max }$ & $\mathrm{T}_{\min }$ & $\mathrm{T}_{\max }$ & $\mathrm{T}_{\min }$ & $T_{\text {max }}$ & $\mathrm{T}_{\min }$ & $T_{\max }$ \\
\hline \multirow[t]{2}{*}{ North } & -2.8 & \multicolumn{2}{|c|}{1.3} & \multicolumn{2}{|c|}{0.1} & \multicolumn{2}{|c|}{-0.6} & \multicolumn{2}{|c|}{0.1} & \multicolumn{2}{|c|}{-0.3} & \multicolumn{2}{|c|}{-1.1} & \multicolumn{2}{|c|}{0.2} \\
\hline & \begin{tabular}{|l|l|}
-3.2 & -2.6 \\
\end{tabular} & 1.3 & 1.4 & -0.3 & 0.0 & -0.6 & -0.6 & 0.2 & -0.1 & 0.0 & -0.2 & -1.3 & -0.8 & -0.1 & 0.1 \\
\hline \multirow[t]{2}{*}{ South } & -1.4 & \multicolumn{2}{|c|}{0.2} & & & & & & & & & & & -0 & 3 \\
\hline & \begin{tabular}{|l|l|}
-1.5 & -1.4 \\
\end{tabular} & 0.2 & 0.3 & -0.8 & $\begin{array}{l}-1.4 \\
\end{array}$ & -1.1 & -1.2 & -0.8 & -1.3 & 0.1 & 0.1 & 0.0 & -0.2 & -0.2 & -0.4 \\
\hline West & $-0 . \overline{8}$ & & & & & & & & & & & & & 0 & \\
\hline & \begin{tabular}{l|l}
$-\mathbf{0 . 8}$ & -0.7
\end{tabular} & 0.6 & 1.0 & -1.4 & -2.0 & -0.7 & -1.2 & -0.2 & -0.4 & 0.3 & 0.3 & -1.4 & -1.9 & 0.1 & 0.8 \\
\hline East & -1.1 & & & & & & & & & & & & & 0 & \\
\hline & -1.3 & 1.4 & 1.2 & 0.3 & -0.2 & -0.4 & -0.4 & -0.6 & -1.4 & -0.1 & 0.5 & 0.0 & -0.2 & 0.6 & 0.6 \\
\hline Central & -1.8 & & & & & & & & & & & & & -1 & .5 \\
\hline & -1.9 & 1.8 & 1.4 & 0.5 & -0.3 & -1.5 & -0.4 & -0.4 & -1.1 & 0.4 & 1.2 & -2.2 & -3.4 & $\begin{array}{l}-1.2 \\
\end{array}$ & -2.1 \\
\hline Anticyclonic & -2.2 & & & & & & & & & & & & & $\overline{-0}$ & .2 \\
\hline & -2.3 & 1.4 & 1.4 & -0.4 & -0.8 & -0.6 & -0.4 & -0.5 & -0.9 & 0.2 & 0.5 & -1.0 & -1.4 & -0.3 & -0.2 \\
\hline Cyclonic & -1.7 & & & & & & & & & & & & & 0 . & \\
\hline & -1.8 & 0.9 & 1.4 & -0.6 & -1.0 & -1.2 & -1.6 & 0.0 & $\begin{array}{c}-0.2 \\
\end{array}$ & -0.1 & -0.5 & -0.5 & $\begin{array}{l}-0.6 \\
\end{array}$ & 0.1 & 0.1 \\
\hline
\end{tabular}

\section{Precipitation}

The NAO- CP joint effect on precipitation of the Carpathian basin is also analyzed. In general, for all seasons, the climate of the Carpathian basin is drier than average during NAO+ phase, and wetter than average during NAO- phase. For this region, similar results are published by [13]. Our results suggest that the NAO+ drying effect is significant in all seasons when either the Central CP class of the Péczely system (the Carpathian basin is drier than average by $37 \%, 52 \%, 73 \%$, and $70 \%$ on century-wise average in winter, spring, summer, and autumn, respectively), or the Southern CP class of the HBGWL system (the average precipitation decrease is $34 \%, 44 \%, 71 \%$, and $15 \%$ in winter, spring, summer, and autumn, respectively) occurs. When using the HBGWL classification system, NAO- is associated with significantly wetter than average climate (by $77 \%, 41 \%, 76 \%$, and $130 \%$ in winter, spring, summer, and autumn, respectively) in case of Half-meridional CP classes. In case of Meridional CP classes, significantly wetter winters and autumns (by $25 \%$ and $35 \%$ on century-wise average, respectively) are observed during NAO-, and drier summers and autumns (by $36 \%$ and $37 \%$ on century-wise average, respectively) during $\mathrm{NAO}+$ phase. In case of zonal $\mathrm{CP}$ classes, only wetter and drier than average winters associated with $\mathrm{NAO}-$ and $\mathrm{NAO}+$ phases, respectively, are significant at 0.05 level.

If considering cyclone or anticyclone dominance over the region, NAO+ is associated with dry winters and summers in case of Anticyclonic CP class, whereas NAO- implies wet winters and autumns in the Carpathian basin (either for the Péczely or the HBGWL classification systems). When Cyclonic CP class occurs (using the HBGWL classification system) both winters and springs are significantly drier than usual (by $19-20 \%$ on century-wise average) in NAO+ phase, and springs and autumns are significantly wetter than average (by $22 \%$ and $59 \%$, respectively) in NAO- phase. If the Péczely classification system is used then Cyclonic CP class is associated with significantly wetter winters and autumns (by $25 \%$ and $22 \%$, respectively) during NAOphase. 
Since the local climatic effect of NAO is most evident in winter [7, 8], this season is selected to illustrate to $\mathrm{CP}$-class-wise average temperature and precipitation differences for the Carpathian basin during NAO- and NAO+ phases relative to the normal conditions (Fig. 2). Significant difference values (at 0.05 level) are indicated by an asterisk near the column. In general, NAO- phase is associated with cold and wet winters, whereas NAO+ phase implies warm and dry winters in the Carpathian basin. Both differences for both phases are significant for the Anticyclonic CP classes (using either the Péczely or HBGWL system) as well, as for the Half-meridional CP class of the HBGWL system. In addition, precipitation-wise differences for both NAO phases are significant when Southern CP classes (using the Péczely classification system), and Western or Zonal CP classes (using the HBGWL system) occur.

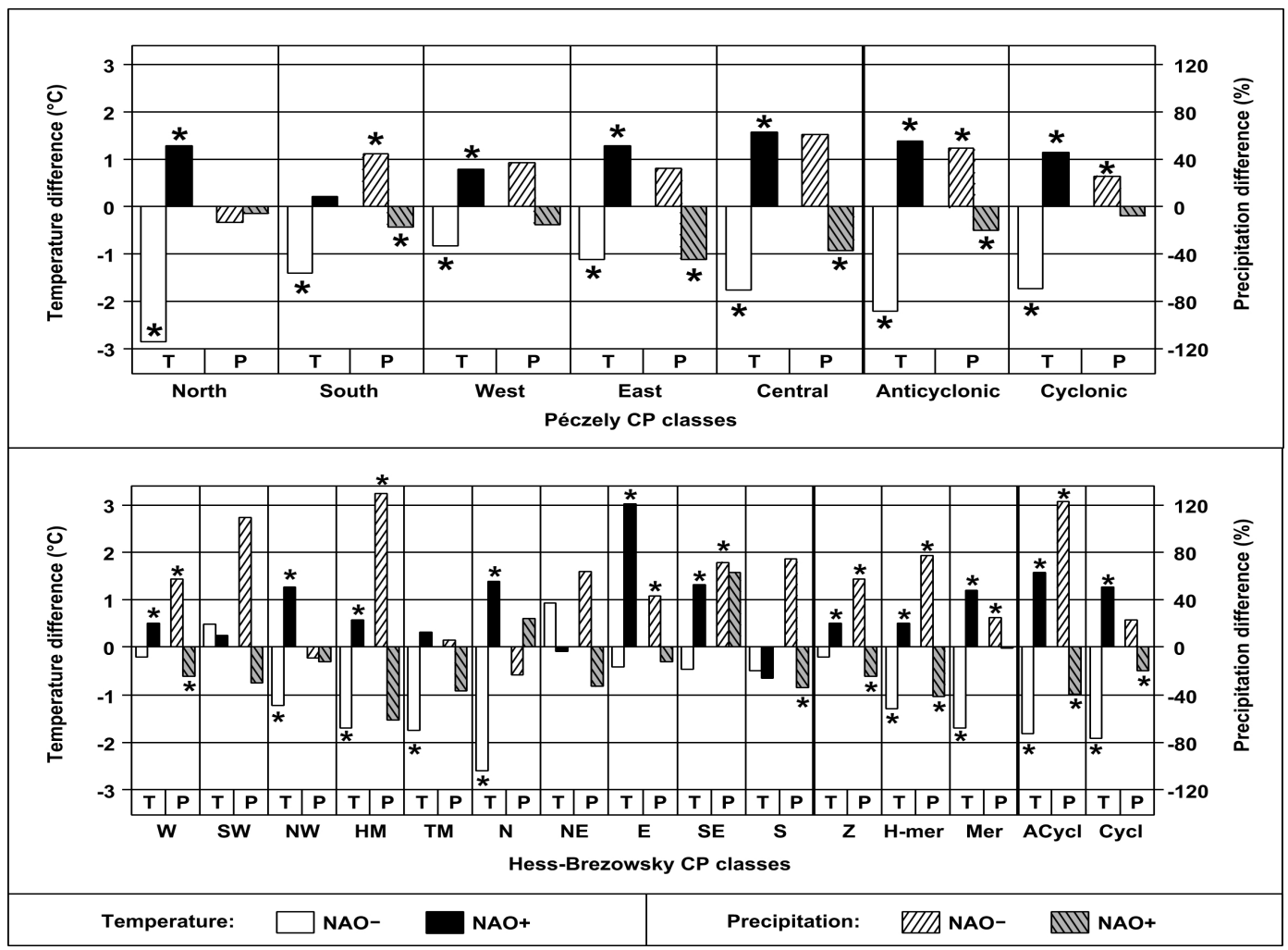

Figure 2. $C P$-class-wise average temperature $\left(T ;{ }^{\circ} C\right)$ and precipitation $(P ; \%)$ differences in winter during the NAO negative and positive phases relative to the normal conditions (defined by the standard deviation). Significant differences at 0.05 level are indicated by an asterisk near the column.

\section{Conclusions}

NAO effects on regional circulation represented by the occurrence of HBGWL and Péczely $\mathrm{CP}$ classes have been analyzed. Then, NAO and CP joint effects on local temperature and precipitation conditions have been evaluated for the 20th century. $\mathrm{NAO}+$ and NAO- phases applied in our analysis have been defined using the standard deviation of the monthly NAO index time series. Based on the results presented in this paper, the following conclusions can be drawn. 
- The zonal/meridional $\mathrm{CP}$ classes occur more often during NAO+/NAO- phase in all seasons in case of both classification systems.

- Cyclonic CP types are more frequent in NAO- phase, and less frequent in $\mathrm{NAO}+$ phase than in case of normal conditions, whereas frequency differences of Anticyclonic CP types are opposite to these.

- The largest frequency difference values between NAO-/NAO+ phases and the normal conditions are observed during winter, which mostly exceed $10 \%$.

- NAO- phase is associated with cold and wet winters, whereas NAO+ phase implies warm and dry winters in the Carpathian basin. This difference is especially manifested when Anticyclonic CP class occur using either the Péczely or HBGWL classification system.

- NAO+ is associated with dry and warm winters, and dry summers in case of Anticyclonic CP class, whereas NAO- phase implies wet and cold winters and autumns in the Carpathian basin (either for the Péczely or the HBGWL classification systems).

- When Cyclonic CP class occurs using the HBGWL classification system winters tend to be drier and warmer than average, and springs tend to be drier and colder than average in NAO+ phase. In addition, springs and autumns tend to be wetter than average, and winters tend to be colder than average in NAOphase.

- If the Péczely classification system is used then Cyclonic CP class is associated with significantly warmer winters and colder springs during NAO+ phase. Furthermore, significantly wetter and colder winters, and wetter autumns occur during NAO- phase.

Acknowledgements. Research leading to this paper has been supported by the following sources: the Hungarian Academy of Sciences under the program 2006/TKI/246 titled Adaptation to climate change; the Hungarian National Science Research Foundation under grants T-49824, K-78125, K-67626, and K69164; the Hungarian Ministry of Environment and Water under the National Climate Strategy Development project; the Hungarian National Research Development Program under grants NKFP3A/082/2004 and NKFP-6/079/2005; the CECILIA project of the European Union Nr. 6 program (contract no. GOCE-037005). Furthermore, support of the Hungarian State Eötvös Fellowship is appreciated.

\section{REFERENCES}

[1] Barnston, A.G., Livezey, R.E. (1987): Classification, seasonality and persistence of lowfrequency atmospheric circulation patterns. - Monthly Weather Review 115: 1083-1126.

[2] Glantz, M.H., Katz, R.W., Nicholls, N., Eds. (1991): Teleconnections Linking Worldwide Climate Anomalies. - Cambridge University Press, New York, NJ.

[3] Glantz, M.H. (1996): Currents of Change: El Nino's and La Nina's Impact on Climate and Society. - Cambridge University Press, New York.

[4] Hess, P., Brezowsky, H. (1952): Katalog der Grosswetterlagen Europas. - Berichte Deutscher Wetterdienst in der US Zone. Bad Kissingen. No. 33. 39.

[5] Hess, P., Brezowsky, H. (1977): Katalog der Grosswetterlagen. - Berichte Deutscher Wetterdienst. Offenbach. 113 Bd 15.

[6] Hurrell, J.W. (1995): Decadal trends in the North Atlantic oscillation regional temperatures and precipitation. - Science 269: 676-679. 
[7] Hurrell, J.W., van Loon, H. (1997): Decadal variations in climate associated with the North Atlantic Oscillation. - Climatic Change 36: 301-326.

[8] Hurrell, J.W., Kushnir, Y., Ottersen, G., Visbeck, M., Eds. (2003): The North Atlantic Oscillation Climate Significance and Environmental Impacts. - Geophysical Monograph Series, 134. American Geophysical Union, Washington DC.

[9] Jones, P.D., Jonsson, T., Wheeler, D. (1997): Extension to the North Atlantic Oscillation using early instrumental pressure observations from Gibraltar and South-West Iceland. International Journal of Climatolology 17: 1433-1450.

[10] Károssy, Cs. (1994): Péczely's classification of macrosynoptic types and the catalogue of weather situations (1951-1992). - In: Nowinsky, L. (ed): Light trapping of insects influenced by abiotic factors. Part I. Savaria University Press, Szombathely. 117-130.

[11] Károssy, Cs. (1997): Catalogue of Péczely's macrosynoptic weather situations (19931996). - In: Nowinsky, L. (ed): Light trapping of insects influenced by abiotic factors. Part II. Savaria University Press. Szombathely. 159-162.

[12] van Loon, H., Rogers, J. (1978): The seesaw in winter temperature between Greenland and northern Europe. Part I: general descrip. - Monthly Weather Review 106: 296-310.

[13] Lopez-Moreno, J.I., Vicente-Serrano, S.M. (2008): Positive and negative phases of the wintertime north Atlantic oscillation and drought occurrence over Europe: A multitemporal-scale approach. - Journal of Climate 21: 1220-1243.

[14] Osborn, T.J. (2006): Recent variations in the winter North Atlantic Oscill. - Weather 61: 353-355.

[15] Péczely, Gy. (1961): Characterising the meteorological macrosynoptic situations in Hungary (in Hungarian). Hungarian Meteorological Service, Budapest. No. 32: 132p.

[16] Péczely, Gy. (1983): Catalogue of macrosynoptic situations of Hungary in years 18811983 (in Hungarian). - Hungarian Meteorological Service, Budapest. No. 53: 116p.

[17] Philander, S.G.H. (1990): El Nino, La Nina, and the Southern Oscillation. - Academic Press, New York, NJ.

[18] Pongrácz, R. (2003): Joint effects of large scale circulation and atmospheric oscillations (ENSO, NAO) on regional climate parameters. PhD thesis. - Eötvös Loránd University, Budapest. 105p.

[19] Rodwell, M.J., Rowell, D.P., Folland, C.K. (1999): Oceanic forcing of the wintertime North Atlantic Oscillation and European climate. - Nature 398: 320-323.

[20] Scaife, A.A., Knight, J.R., Vallis, G.K., Folland, C.K. (2005): A stratospheric influence on the winter NAO and North Atlantic surface climate. - Geophysical Research Letters 32: L18715, doi:10.1029/2005GL023226.

[21] Serreze, M.C., Carse, F., Barry, R.G., Rogers, J.C. (1997): Icelandic low activity: climatological features, linkages with the NAO, and relationships with recent changes in the Northern Hemisphere circulation. - Journal of Climate 10: 453-464.

[22] Trigo, R.M., Osborn, T.J., Corte-Real, J.M. (2002): The North Atlantic Oscillation influence on Europe: Climate impacts and associated physical mechanisms. - Climate Research 20: 9-17.

[23] Vinther, B.M., Andersen, K.K., Hansen, A.W., Schmith, T., Jones, P.D. (2003): Improving the Gibraltar/Reyjavik NAO Index. - Geophysical Research Letters 30(23): 2222, DOI doi:10.1029/2003GL018220.

[24] Wallace, J.M., Gutzler, D.S. (1981): Teleconnections in the geopotential height field during the Northern Hemisphere. - Monthly Weather Review 109: 784-812.

[25] Wanner, H., Brönnimann, S., Casty, C., Gyalistras, D., Luterbacher, J., Schmutz, C., Stephenson, D.B., Xoplaki, E. (2001): North Atlantic Oscillation - concepts and studies. Surveys in Geophysics 22: 321-381. 